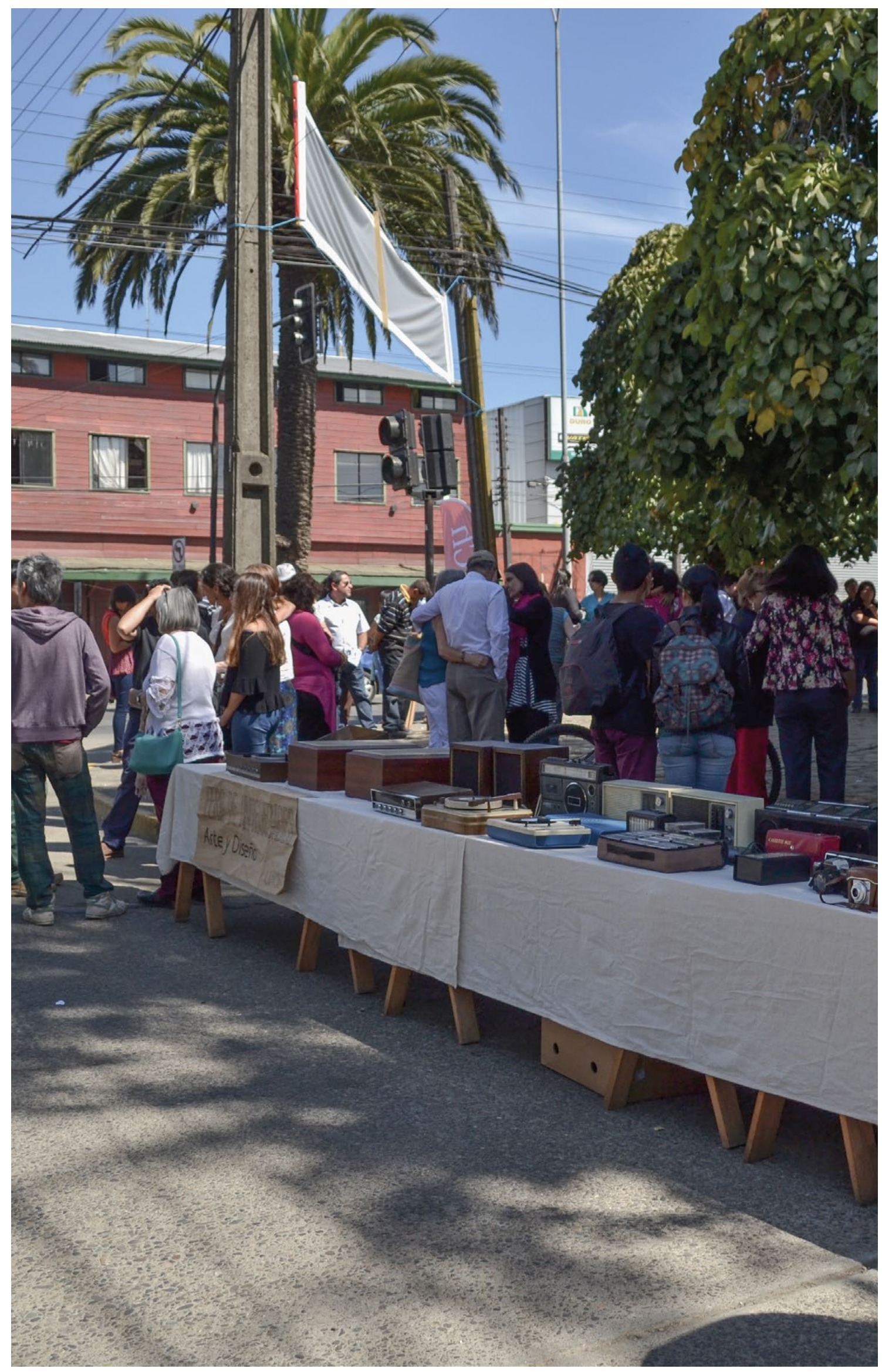

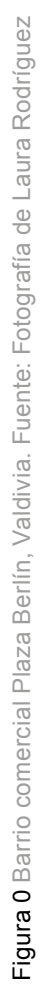



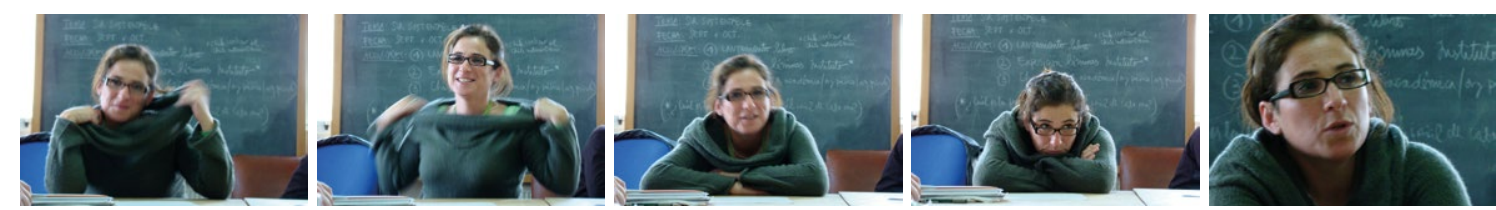

\title{
PRINCIPIOS DE DISEÑO URBANO Y CONSTRUCCIÓN DE SENTIDO EN LOS BARRIOS COMERCIALES'
}

\author{
PRINCIPLES OF URBAN DESIGN AND MAKING THE MEANING OF COMMERCIAL \\ DISTRICTS
}

Laura Rodriguez Negrete ${ }^{2}$

RESUMEN

\begin{abstract}
Las problematizaciones acerca del sentido de los barrios comerciales es el asunto abordado en esta investigación. Visto desde los principios de diseño urbano, campo de estudio ubicado dentro del urbanismo semiótico, ella profundiza en el sentido y la capacidad de los lugares de adquirirlo. Enfocándose en el caso de los barrios comerciales, conceptualiza los principios de diseño urbano más recurrentes en los barrios comerciales (vitalidad, memoria y versatilidad), examinando su relación con el espacio público aledaño. Asimismo, el artículo examina, a través del estudio de tres ciudades, la forma en la cual se materializan los tres fundamentales principios de diseño urbano encontrados en dichos lugares. Considerando el importante rol que tales principios cumplen con relación al espacio público aledaño a estos barrios, se ha evidenciado que además son significativos para la construcción del sentido de pertenencia de las comunidades que los habitan y usan.
\end{abstract}

Palabras clave: barrios comerciales, diseño urbano, semiótica, espacio público, identidad.

\section{ABSTRACT}

This research addresses the problematization of the meaning of commercial districts. As viewed from the principles of urban design, a field of study located within urban semiotics, it analyzes sense of place and the ability to acquire it. Focusing on the case of commercial districts, this study conceptualizes the most recurrent urban design principles in commercial neighborhoods (vitality, memory and versatility), examining their relationship with the surrounding public space. Likewise, through a case study of three cities, the article examines the way in which the three main principles of urban design found in these places are materialized. Considering the important role that such principles play in relation to the public space adjacent to these neighborhoods, it is also shown that they are significant for the construction of the sense of belonging of the communities that inhabit and use them.

Keywords: commercial districts, urban design, semiotics, public space, identity.

Artículo recibido el 21 de octubre de 2016 y aceptado el 18 de mayo de 2017 DOI: https://doi.org/10.22320/07196466.2017.35.051.04

[1] Este artículo se basa en los resultados de investigación del proyecto Fondecyt de iniciación N 11130293. "El diseño urbano: aproximaciones desde la identidad y el sentido de lugar en las ciudades de Concepción y Talca".

[2] Instituto de Arquitectura y Urbanismo, Facultad de Arquitectura y Artes,Universidad Austral de Chile, Valdivia, Chile. Irodriguez@ uach.cl 


\section{INTRODUCCIÓN}

¿Cómo los negocios manufacturan el sentido? Es la pregunta que se hace Ernst Sternberg (1999) en su libro La economía de los iconos, ya que en su opinión es la imagen, y no la información, la fuerza conductora de las nuevas economías. Esto se debe, según Nelson Goodman (1968), a que los objetos ordinarios adquieren un significado figurativo extraordinario en la medida que nosotros, como espectadores, compartimos una capacidad humana fundamentalmente simbolizadora. Tal cual lo hacían las sociedades antiguas, la economía, como una actividad inserta en la vida cotidiana de los individuos, está permeada por la magia y el mito, a pesar de la racionalidad que ésta clama. La producción de sentido en la economía puede ser observada, por ejemplo, desde el proceso de producción y comercialización de la uva en conjunto con el vino (Lacoste, 2005; Rocchi y Gabbai, 2013; Charters y Michaux, 2014), hasta la transformación de las ciudades y sus consiguientes barrios, e incluso regiones enteras, en territorios con identidad y sentido, (Edizel, 2013; Peattie y Samuel, 2015; MuñizMartínez, 2012).

Los barrios comerciales también tienen un sentido, y lo evidente es pensar que lo adquieren en función de su actividad económica, encarnada en el consumo exclusivamente. Sin embargo, existen los llamados "principios de diseño urbano" (PDU), involucrados en este proceso, que explican la razón subyacente al sentido que estos barrios puedan tener para la ciudadanía. Este artículo conceptualiza los lugares con sentido, poniendo énfasis en los PDU que contribuyen a dotar de sentido a los barrios comerciales examinados en los casos de estudio. La investigación se orienta al rol del espacio público como soporte de las actividades cotidianas que se dan en conjunto con el intercambio comercial, concibiéndose ese espacio público no solo a través del emplazamiento de plazas y parques, sino también desde la calle, como eje principal del intercambio socio-económico. Así, el papel del espacio público en la construcción de sentido de los barrios comerciales, se discute en este trabajo desde tres principios de diseño urbano: la vitalidad, la memoria y, por último, la versatilidad. 


\section{METODOLOGÍA}

Este artículo entrega una nueva aproximación al sentido de los barrios comerciales y a la forma de explicarlos. Inicialmente, se conceptualiza los lugares con sentido -materia abordada profusamente por la geografía cultural- elaborando una reflexión crítica respecto de ellos, para posteriormente examinar la racionalidad detrás del sentido que rodea a los barrios comerciales. Argumentando, a partir de resultados de investigaciones previas en distintas ciudades, se conceptualizan los principios de diseño urbano (PDU) más recurrentes que permiten entender el sentido que tienen los barrios comerciales (vitalidad, memoria y versatilidad).

A partir de investigaciones previas ${ }^{3}$, se toman, como caso de estudio, los paseos peatonales de las ciudades de Concepción y Talca, en tanto estos forman parte del sistema de lugares con sentido encontrados por Rodríguez y Carrasco (2016), y se sugiere una explicación a la selección realizada, como parte de una política pública, del barrio comercial, Plaza Berlín (Valdivia). Los principios de diseño urbano considerados en este trabajo son básicamente los recopilados por trabajos de Sternberg (2007) y otros autores situados bajo una aproximación semiótica del urbanismo. "La semiología urbana estudia la transferencia de significados existentes en las formas construidas de la ciudad. La condición semiológica es cultural, subjetiva y muchas veces abstracta" (Munizaga, 2014: 171). Desde este enfoque, se sitúa a la forma urbana como "un medio comunicante", que, vale aclarar, no es enteramente subjetivo, ya que en rigor la transferencia comunicativa se da en una forma intersubjetiva. Quienes perciben la ciudad lo hacen también sobre la base de un cierto consenso respecto de lo que representa el espacio urbano.

\section{Sobre el sentido de los lugares}

El sentido de los lugares constituye una materia ampliamente examinada dentro de la Geografía Cultural y se ha venido ubicando en un punto de encuentro con los nuevos intereses de la Geografía Política (Jones, et al., 2015). Desde una aproximación fenomenológica del espacio, al incorporar la experiencia humana como elemento sustantivo e interpretable, se discuten las conceptualizaciones del lugar, desde lo cultural y lo político (Tuan: 1974; Fernández, 2006; Shmite y Nin: 2006-2007).

Dentro del amplio espectro de lo que se podría considerar urbano, existen aún esos lugares significativos que representan en el imaginario urbano el deseo de una urbanidad trascendente y participativa. Lugares que adquieren su condición de tal, de acuerdo al enfoque de la geografía humanista, porque tienen un significado compartido. La contribución de autores como Tuan (2001) es, en este sentido ineludible, tal como la perspectiva de las geógrafas feministas, al problematizar el sentido de lugar en el hogar (McDowell: 1994; Rose: 1995; McDowell and Sharp: 1997). De la misma forma, son cardinales los aportes de Creswell (2010) respecto de lo fuera de lugar y la exclusión, y las contribuciones de Massey (1994), quien aborda el sentido de lugar bajo un contexto de globalización de las relaciones, evidenciando las conexiones globales y la re-significación de los lugares derivado de este proceso.

Pero los lugares con sentido también son comprendidos aquí desde la perspectiva de la teoría del sentido, del filósofo chileno Cristóbal Holzapfel (2005), quien conceptualiza a las fuentes que le dan sentido a la existencia. Holzapfel, define teoréticamente la existencia de fuentes dispensadoras que le dan sentido a la existencia, dentro de las cuales estarían, en primer término, las referenciales de carácter universal, tales como: el amor, la creatividad, la muerte, la familia, el trabajo, el juego, el poder. En segundo lugar, se hallan las programáticas, de carácter histórico, como la religión, la ciencia, la política, la filosofía, la economía, la historia. Y, finalmente, están las ocasionales, las que corresponden "al sentido que se genera a partir de, precisamente, ocasiones, momentos, oportunidades pasajeras y azarosas, como la ocasión de estar de paseo o de viaje con un grupo con el cual compartimos distintas experiencias; la ocasión de ver una película o de leer un libro" (Ibídem, 144). El filósofo indica además que las fuentes icónicas serían las materializadoras del sentido, revelan la cualidad de sustancializarse del sentido. Dentro de espacio urbano, algunas fuentes de sentido ocasional, de acuerdo a Rodríguez (2012), se localizan en lugares que poseen un sentido ocasional, singularmente en los espacios públicos donde se llevan a cabo las celebraciones, manifestaciones, intercambios sociales, económicos y un sinfín de actividades sociales.

Aun cuando el filósofo citado establece que "con las fuentes icónicas ocurre algo similar que con las fuentes ocasionales: su clasificación es imposible; tan solo se puede dar ejemplos" (Holzapfel, 2005:55), examinar el encadenamiento con las fuentes referenciales y programáticas, es la clave explicativa respecto de su capacidad de dotar de sentido a los lugares de la ciudad. En un lenguaje un tanto diferente, bajo lo que Munizaga (2014) denomina "urbanismo semiótico", esta materia ha sido abordada por teóricos del diseño urbano (Sternberg, 2007; White, 1999).

La producción de sentido en el esquema actual de las ciudades contemporáneas, sin duda está penetrado por el capital y sus múltiples y complejas estrategias de expansión. Por lo que existe una fuerte crítica en esta temática, cuya vertiente principal considera perjudicial transformar todo en objeto de consumo, incluido el sentido de los lugares. Siguiendo esta argumentación, es posible advertir que los lugares se convierten en espectáculo de consumo, utilizándoseles de esa manera para el marketing territorial. Zukin manifiesta que "nuevas arquitecturas y formas urbanas son, más que nada, producidas bajo las mismas condiciones sociales que los productos de consumo" (2003: 178). Con esto último, se persigue la construcción y manipulación de la identidad no solo cultural, sino también territorial, lo que se lleva a cabo incluso a través de la invención de ciertas tradiciones con el fin de consolidar una comunidad imaginada (Nasser, 


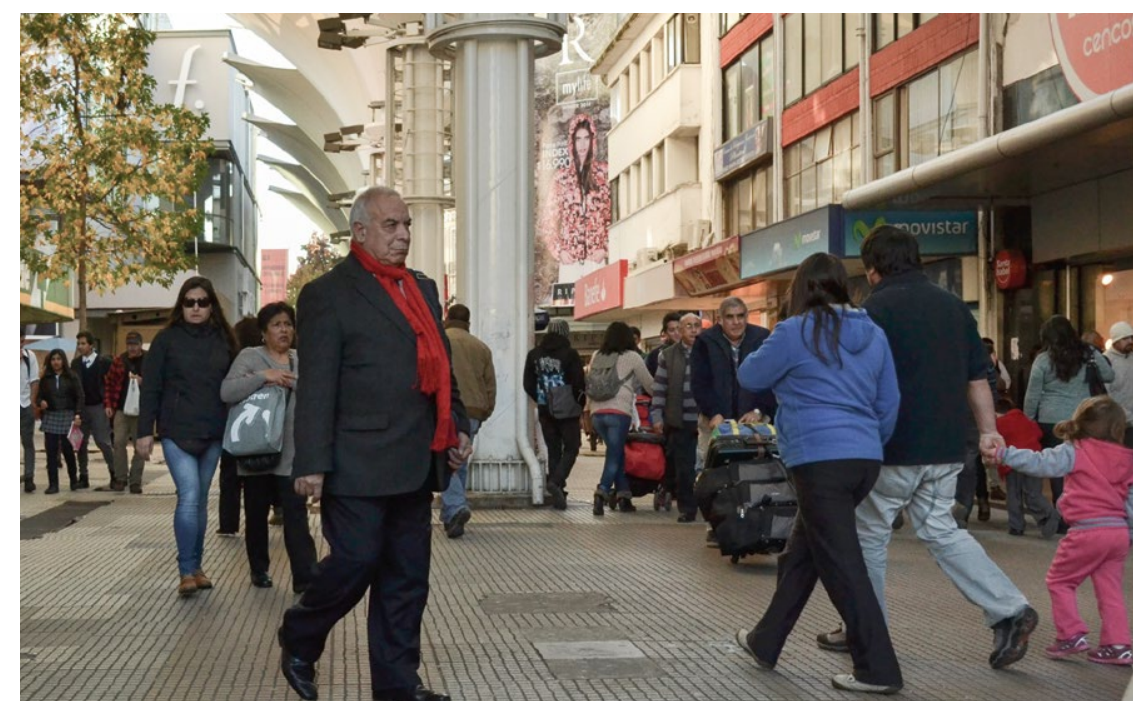

Figura 1 Paseo Barros Arana, Concepción. Fuente: Fotografía de Laura Rodríguez

2003). Muchas veces la recuperación mimética del paisaje produce un remedo que da origen al espectáculo y al simulacro: un "paisaje de autor", como si del mundo de culinario se tratase. Lorente, Antolin y Fernández parecen concordar con esta idea cuando expresan que:

El mapa precede al territorio, tal como el proyecto preced a la ciudad proyectándola hacia el futuro, desplegando un simulacro que no trata más de representar la ciudad y lo real, sino más bien persigue su reconstrucción con lo material de los signos. Sin embargo, es ahora una cuestión de signos que han cambiado "desde la disimulación de algo a signos que disimulan donde no hay nada" (Baudrillard, 1978:15). Aquí el límite entre lo real y lo imaginario llega a ser difuso y mezclado. En "sim-cities" (ciudades simuladas), para usar la expresión de Edward Soja, la simulación de la planificación urbana es ingeniosamente confusa con el territorio, adquiriendo su capacidad de erigir e imponer una narrativa de proyecto en el cual están inscritos maneras hyperreales y estilos de vida, y donde, como en un parque temático, los individuos se relacionan entre sí, comen, se visten y comportan. (2007: 146)

En este contexto, la ciudad pasó a ser otro objeto de consumo más debido a su particular propiedad de generar, entre otros capitales, el capital simbólico, el cual es entendido por Bourdieu como "un capital económico o político desautorizado, no reconocido y así [de esta manera] reconocido, por lo tanto legitimado, "un crédito" el cual, bajo ciertas condiciones, y siempre en el largo plazo, garantiza un beneficio económico" (1993:75). En efecto, y tal como explica Cuthbert, "La producción del capital simbólico está también cercanamente relacionada a la producción del capital cultural y la economía cultural como un todo. En el proceso de diseño urbano este usualmente significa la habilidad de capturar algunos aspectos del desarrollo histórico y o cultural, y el deseo de empaquetarlos para la venta de algún tipo de nuevas experiencias que reinterpreten o transciendan lo viejo" (2006:190).
Recapitulando, pareciera ser que todo en la ciudad se convierte en una posibilidad de consumo, incluso hasta las actividades y prácticas ajenas del capital o al menos en la periferia de este. De este modo, la ciudad se transforma, flexibilizando sus estructura, redescubriéndose en un proceso distintivo de destrucción creativa, tensionada como espacio de contestación y adaptación social, distinta al abordado inicialmente por Schumpeter (1994).

No obstante, esta no es la única conceptualización posible, los lugares también han adquirido sentido a través de la significancia comunitaria. El poder de un lugar, dice Dolores Hayden (1997), radica en conectar la política de la identidad étnica y del género a los esfuerzos de la preservación histórica urbana, distinguiendo las señales de la memoria colectiva en el paisaje urbano y la solidaridad de los grupos, de los cuales se pueden extraer recursos morales y políticos. Este es el poder de un lugar, del cual también habla Zukin: "A pesar de que una nueva identidad del lugar puede contradecir a los elementos del pasado de las áreas -y [aun así] presentarse como respetuosa de la autenticidad de la comunidad- las redes sociales y culturales de los nuevos productores y consumidores crean, nutren, $y$ con frecuencia capitalizan en un sentido del lugar completamente nuevo" (2011:164).

En una investigación previa (Rodríguez y Carrasco, 2016) se ha determinado que en el caso de Concepción y Talca, existe un sistema de lugares con sentido, fortalecedor del sentido de pertenencia de los habitantes, puesto que está íntimamente articulado con la identidad de la ciudadanía. Dentro de este sistema, las vías peatonales juegan un rol significativo y central, no solo porque se constituyen como barrios de consumo de bienes y servicios, sino también porque evidencian aspectos relevantes de la identidad de las ciudades. 


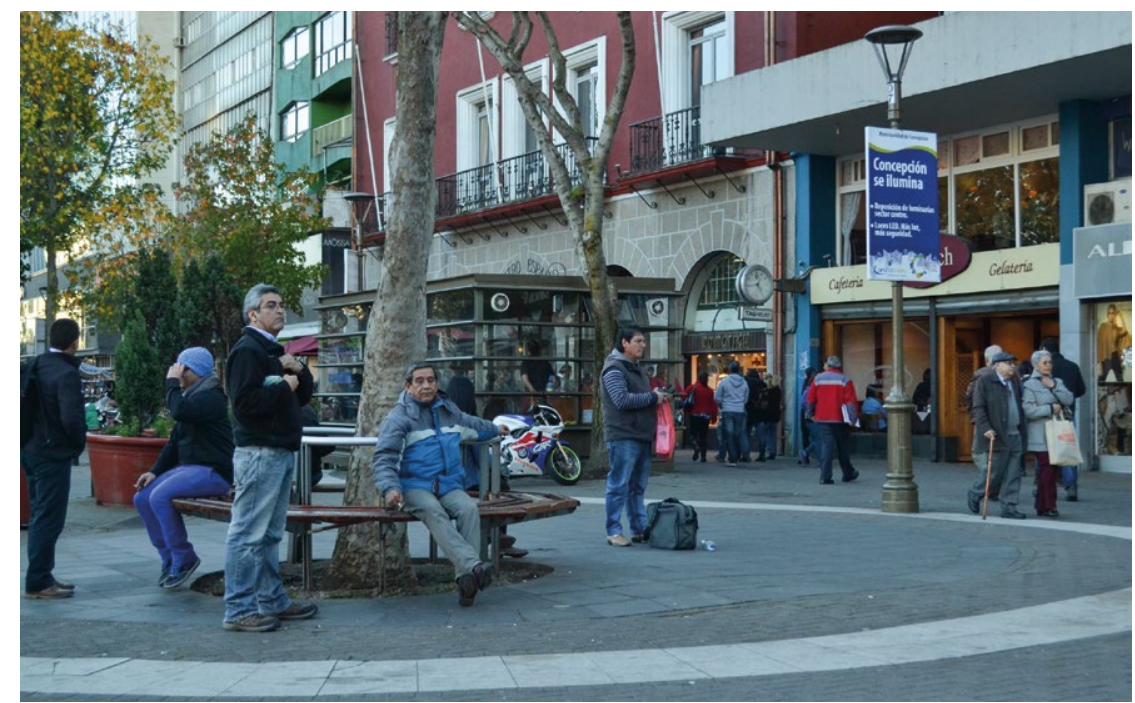

Figura 2 Paseo peatonal Barros Arana ("Esquina de los tontos"), Concepción. Fuente: Fotografía de Laura Rodríguez

\section{Del sentido en los barrios comerciales}

Los espacios comerciales en las ciudades chilenas, y con gran probabilidad en el resto del mundo, están asociados a la venta de bienes y servicios demandados por un público que además se ha vuelto un consumidor cada vez más exigente de imágenes. “Más aún, las imágenes, en un sentido, se han convertido en mercancías. Este fenómeno ha llevado a Baudrillard (1981) a sostener que el análisis de la producción de mercancías de Marx está pasado de moda porque hoy el capitalismo se dedica sobre todo a la producción de signos, imágenes y sistemas de signos y no a las mercancías en sí mismas" (Harvey: 1990:318).

Lo anterior forma, en parte, el diagnóstico y la propuesta de una reciente política pública chilena denominada Fortalecimiento de los Barrios Comerciales. Siendo un programa de creación reciente, aún no ha sido examinado críticamente su gestión por medio de publicaciones científicas. En una primera etapa, esta iniciativa conjunta entre el Ministerio de Economía y el Ministerio de Vivienda y Urbanismo, se encuentra en una fase de organización del capital social y económico de los 60 barrios seleccionados en todo Chile. El desafío planteado es abordar el desarrollo local, posicionando aspectos como la identidad y la inclusión dentro de la economía urbana.

Ahora bien, es cierto que existen fuertes críticas a posicionar el consumo por sobre otros ámbitos de la vida social, y sobre todo a ubicarlo como eje central de la construcción de la identidad, tal como lo observa Larraín en su libro "La identidad chilena": "El sujeto de esta nueva identidad es lo que Moulian ha llamado "el ciudadano credit-card" cuya base de sustentación es el consumo: "la cultura cotidiana del Chile actual está penetrada por la simbólica del consumo", el consumo es lo que le da sentido a la vida de las grandes mayorías" (2001: 164).

Es precisamente considerando la crítica previa, que se hace urgente plantear ciertas interrogantes respecto del sentido de estos barrios comerciales, de tal forma de exa- minar las maneras en que sus significaciones son creadas, transformadas, negociadas, tal como el rol que les cabe en la construcción de nuestras identidades futuras. Así, la política pública mencionada podría articular, de manera más integral, el desarrollo futuro de estos barrios con la identidad y el sentido de pertenencia de sus habitantes.

Uno de los sectores urbanos contemporáneos más asociados al comercio actualmente lo constituyen los paseos peatonales. Ejes viales, reconocidos por ser lugares con sentido ya que atrapan ciertos rasgos de la identidad sumergida y latente de la ciudad. Son lugares atractivos para el intercambio de bienes y servicios, pero también porque se desarrollan actividades que contribuyen a fortalecer el sentido de pertenencia de la comunidad que los habita. Es justamente lo que describe Rosales (2015) en una investigación sobre Concepción y Talca. La Figura 1 muestra la vitalidad presente en el paseo peatonal Barros Arana, Concepción, que ha devenido parte importante del imaginario de la ciudad, a través de la denominación de Eje Bicentenario.

La vitalidad, principio de diseño urbano más recurrente en los barrios comerciales en general y, en particular en los paseos peatonales, es entendida como la situación de dinamismo actual, constituido por la presencia de un conglomerado permanente de público que hace uso de bienes y servicios en un lugar determinado. "Una ciudad vital sugiere una ciudad llena de vida, dinamismo, con una tendencia de vanguardia o de salud pública y de riqueza" (Tunström: 2007:685). La percepción de la vitalidad en estos paseos peatonales se da, sin duda, por el número de personas que circulan en el sector, lo que hace que sean saludables y aun cuando el tramo no siempre es completamente vital, la mayor parte de tiempo está suficientemente repleto de público para evidenciar tal principio. En la Figura 2 se observa la esquina de Barros Arana y Aníbal Pinto, donde convergen no solo un par de paseos peatonales, sino también una memoria asociada al lugar. 

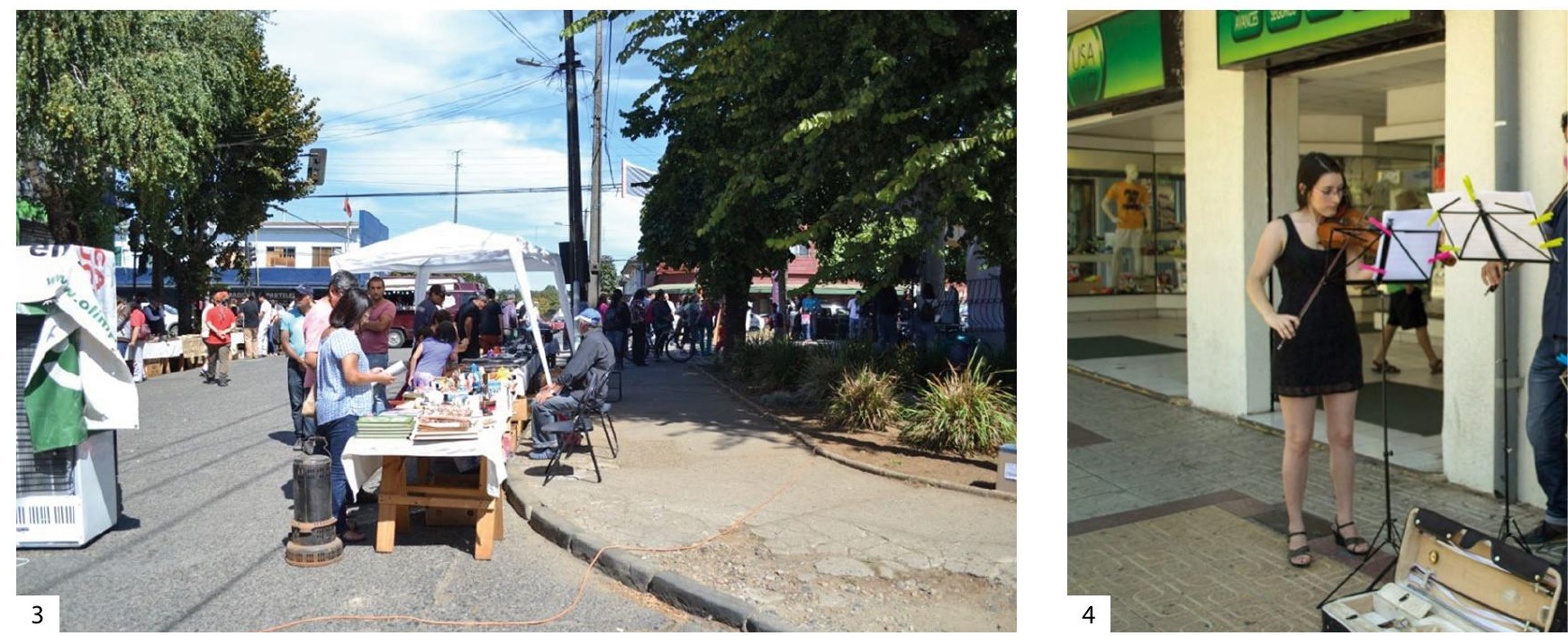

Figura 3 Barrio comercial Plaza Berlín, Valdivia. Fuente: Fotografía de Laura Rodríguez / Figura 4 Artistas callejeros en Paseo Uno Sur, Talca. Fuente: Fotografía de Laura Rodríguez / Figura 5 Actividad cultural en Paseo peatonal Uno Sur, Talca. Fuente: Fotografía de Laura Rodríguez

El sector económico de servicios, en términos generales, se ve favorecido con este tipo de intervención vial y aun cuando las cadenas de grandes tiendas, muchas de ellas globalizadas, se localizan en estos lugares, también sobreviven negocios locales que suplementan la economía familiar (Ravenscroft, 2000). Siendo estos negocios locales, menos proclives de subsistir dentro de la economía globalizada y a escala de la ciudad contemporánea, categóricamente tienen mejores oportunidades en condiciones distintas (Yi, Batra y Siqing: 2015). La peculiaridad, traducida en ventaja, se constituye al darle un sentido al emprendimiento (Krupa y Lysaght, 2016).

Al respecto, Rodríguez (2016) sugiere que los paseos peatonales en las ciudades de Concepción y Talca no solo pueden ser explicados desde la vitalidad, uno de los PDU, sino que hay otros principios involucrados, que hacen que estas peatonales sean lugares con sentido para las ciudades examinadas: la memoria y la versatilidad del espacio público de dichas ciudades. Efectivamente:

\begin{abstract}
Las peatonales en ambas ciudades son lugares con sentido, sentido que ha sido construido a través de una serie de atributos que no solo son físicos, sino en gran medida en la interacción de la gente con el medio. No solo se observa la vitalidad reducida al consumo de bienes y servicios, como principio de diseño urbano explicativo de las peatonales, sino que entregan una serie de atributos que las convierten en grandes calles. (Rodríguez, 2016: 215)
\end{abstract}

Condición mencionada también por Capellá (2014) en referencia a un lugar ubicado dentro del eje peatonal Barros Arana, en Concepción:

En el presente caso de análisis de La parada del Tonto, el referente no solo se puede entender como un lugar para la memoria colectiva penquista, sino que metafó- ricamente podemos comprender que, tras el topónimo vinculado al lugar, existiría una forma de memoria del lugar. La pervivencia y transmisión del nombre de los lugares (topónimos) significa no solo la supervivencia de un referente colectivo urbano, sino que también constituye, en el caso de Concepción, una forma de patrimonio invisible y flexible perdurable por su transmisión colectiva, que se adecua al carácter efímero de las formas físicas, sujetas a los caprichos de una considerable naturaleza telúrica como la propia de la región. La memoria de los lugares representa la identidad como referencia colectiva en un compromiso necesario para las sucesivas reconstrucciones materiales. La herencia del referente transmitido (la memoria) es la que permite la permanencia física del lugar. (2014:103)

Los esfuerzos por territorializar la memoria en el espacio urbano, como es el caso descrito anteriormente, pueden ser leídos como una voluntad por honrar las prácticas sociales que construyen finalmente, entre otros factores, el sentido de pertenencia de una comunidad. El discurso identitario patrimonial se vuelve el eje pivotante sobre el que se articula el recurso material. Esta misma narrativa incentiva, mediante prácticas performáticas, el surgimiento de nuevos intereses que atraen nuevos usuarios y al mismo tiempo desplazan a otros. Schindel (2009) las denomina estrategias locales performativas de marcación de la memoria en el espacio.

La memoria de lo acontecido permite ir conformando, a la medida de la ecuación memoria y olvido, lugares significativos. Al ponderar el peso del olvido, surgen entre las diversas colectividades la necesidad por restituir el valor, aun cuando no sea el original. Ello ocurre, en opinión de Till (2008), por el enorme potencial creativo que tiene el espacio-tiempo y la memoria-olvido. Los lugares de la memoria son reclamados y traídos nuevamente al presente, experimentando en algunas ocasiones alguna alteración en su función. 
En esta investigación se han conceptualizado los lugares con sentido, fijando las coordenadas desde los enfoques de la geografía cultural y política. Ello se complementa con una discusión desde la filosofía y los estudios urbanos considerando investigaciones recientes respecto del sentido en la conceptualización de ciudades chilenas.

La interrelación entre las anteriores reflexiones y el surgimiento de una nueva política pública llamada "Fortalecimiento de Barrios Comerciales" ha entregado un lugar para el debate, de manera de entender las circunstancias que rodean al sentido dentro de estos barrios, como también el rol que le cabe al proyecto arquitectónico-urbano en la definición de políticas que promueven ciudades abocadas a fortalecer la vida pública, en sintonía con los contextos económicos y sociales locales.

El proceso significador de los barrios comerciales se ha definido a partir del examen de tres principios de diseño urbano comúnmente presentes en dichos barrios: la vitalidad, la memoria y la versatilidad. Desde luego, estos establecen una interdependencia en el proceso productor de sentido en los espacios señalados. Considerando la fortaleza que dichos principios tienen sobre el espacio público aledaño a estos barrios, se ha evidenciado que son significativos para la construcción del sentido de pertenencia de las comunidades que habitan y usan estos lugares. Así, ellos juegan un papel clave al convertir estos sectores de las ciudades en lugares con sentido que, a pesar de ser ocasionales, se distinguen como lugares icónicos de los espacios urbanos. La oferta de bienes y servicios que entregan los vuelve entornos atractivos de ser visitados. Pero, además, se da en los tres casos estudiados un proceso de configuración de la memoria, a partir de la estación de tren, ubicada en las cercanías de las zonas estudiadas. Lo que se constituye como un proceso de traslado del pasado al presente, capturando ámbitos insignes de la vida urbana. Por último, la morfología urbana también ha permitido que el espacio sea versátil para alojar actividades que se nutren del público asistente y aun cuando son ocasionales, como casi todo lo que sucede en el espacio público, contribuyen a forjar lazos solidos entre sus habitantes. De esta forma, se entiende que los barrios comerciales, incorporados o no dentro del programa de barrios comerciales, son fundamentales en la construcción del sentido de pertenencia de las comunidades, y no tan solo por ofrecer bienes y servicios, sino también por articularse dentro de procesos que involucran el imaginario social y la espacialidad del lugar y que en última instancia van construyendo la identidad de los territorios.
BAUDRILLARD, Jean. Cultura y Simulacro. Barcelona: Editorial Kairos, 1978.

BOURDIEU, Pierre. The field of cultural production essays on art and literature. UK: Polity Press, 1993.

CHARTERS, Steve y MICHAUX, Valery. Special Issue: Clusters, governance and territorial branding in the wine industry, Journal of Wine Research, 2014, vol. 25, $\mathrm{n}^{\circ} 1, \mathrm{pp} .1-61$.

CUTHBERT, Alexander. The form of cities political economy and urban design. Australia: Blackwell Publishing, 2006.

FERNÁNDEZ, Federico. Geografía cultural. En: Hiernaux, Daniel y Lindon, Alicia (eds.). Tratado de Geografía Humana. Iztapalapa: Anthropos, 2006, pp. 220-253.

GOODMAN, Nelson. Languages of arts: an approach to a theory of symbols. Indianapolis, IN: Bobbs-Merrill, 1968.

HARVEY, David. The condition of postmodernity. Cambridge: Blackwell, 1990.

HAYDEN, Dolores. The power of place urban landscapes as public history. Massachusetts: The MIT Press, 1997.

HOLZAPFEL, Cristóbal. A la búsqueda del sentido. Santiago: Editorial Sudamericana, 2005.

JONES, Martin; JONES, Rhys; WOODS, Michael; WHITEHEAD, Mark; DIXON, Deborah y HANNAH, Matthew. An introduction to political geography, space, place and politics. London and New York: Routledge, 2015.

$\mathrm{KIM}$, Annette. The mixed-use sidewalk, Journal of the planning association, 2012, vol. 78, n 3, pp. 225- 238.

KRUPA, Terry y LYSAGHT, Rosemary. Perspectives on How Social Business Can Engender Work Identity Among People with Mental Illness, Journal of Policy Practice, 2016, vol. 15, n 1-2, pp. 36-57.

LACOSTE, Pablo. El vino y la nueva identidad de Chile, Universum (Talca), 2005, vol. 20, n², pp. 24-33.

LARRAÍN, Jorge. Identidad chilena. Santiago: Editorial LOM, 2001.

LORENTE, José; ANTOLIN, José y FERNÁNDEZ, José. The Image of Urban Regeneration Concerning Bilbao: The City as Narrative and Experience, Revista Zer, 2007, n 1, pp. 141- 166.

MASSEY, Doreen. Space, place and gender. Minneapolis: University of Minnesota press, 1994.

MCDOWELL, Linda. The transformation in cultural geography. En: Gregory, D.; Martin, R. y Smith G. (eds.) Human Geography society, space and social science. London: Macnillan press, 1994, pp. 146-173.

MCDOWELL, Linda y SHARP, Joan. Space, gender, Knowledge. New York: John Wiley and sons, 1997. 
MUNIZAGA, Gustavo. Diseño urbano teoría y método. Santiago: Ediciones Universidad Católica de Chile, 2014.

MUÑIZ-MARTÍNEZ, Norberto. City marketing and place branding: A critical review of practice and academic research, Journal of Town \& City Management, 2012, vol. 2, n4, pp. 369-394.

NASSER, Noha. Planning for urban Heritage places: Reconciling conservation, tourism and sustainable development, Journal of planning literature, 2003, vol. $17, n^{\circ} 4$, pp. 467- 479.

PEATTIE, Ken y SAMUEL, Anthony. Places where people matter: The marketing dynamics of Fairtrade Towns. Social Business, 2015, vol. 5, n 3, pp. 237-254.

RAVENSCROFT, Neil. The vitality and viability of town centres, Urban studies, 2000, n 13, pp. 2533-2549.

ROCCHI, Benedetto y GABBAI, Manuela. Territorial identity as a competitive advantage in wine marketing: a case study, Journal of Wine Research, 2013, vol. $24, n^{\circ} 4$, pp. 291-310.

RODRÍGUEZ, Laura. La ciudad como fuente icónica del sentido: prácticas discursivas de la cultura geográfica en las ciudades de Buenos aires, Santiago y Valdivia. Tesis doctoral. Valdivia: Universidad Austral de Chile, 2012.

RODRÍGUEZ, Laura. La ciudad como fuente icónica del sentido: aproximaciones desde la cultura geográfica en Valdivia, AUS, 2013, n¹4, pp.15-18.

RODRÍGUEZ, Laura. Identity and Urban Design: the path to meaningfulness in the city of Concepción Focus Journal of the City and Regional Planning Department, Cal Poly, 2015, n 12, pp. 19-26.

RODRÍGUEZ, Laura. Del sentido en las peatonales: memoria, vitalidad y otras cualidades. En: Inzulza, Jorge; Maragaño, Andrés; Boano, Camillo y Díaz, Ibán (eds.). Gentrificación en Reconstrucción de ciudades intermedias globales. Talca: Ediciones Universidad de Talca, 2016. En prensa.

RODRÍGUEZ, Laura y CARRASCO, Benjamín. Lugare con sentido, identidad y teoría urbana: el caso de las ciudades de Concepción y Talca, Revista de Geografía Norte Grande, 2016, n 64, pp. 167-186.

ROSALES, Nicolás. Lo urbano/lo identitario. Relato de paseos. Miramiento de Talca y Concepción. Tesis para optar al grado de Antropólogo, Universidad Austral de Chile, Valdivia, 2015

ROSE, Gillian. Place and identity: a sense of place. En: Massey, Doreen y Jess, Pat. A place in the world? places, cultures and globalization. New York: Oxford University Press Inc, 1995, pp. 87-118.

SCHINDEL, Estela. Inscribir el pasado en el presente: memoria y espacio urbano, Política y Cultura, 2009, n³1, pp. 65-87.

SCHUMPETER, Joseph. Capitalism, Socialism and Democracy. Londres y Nueva York: Routledge, 1994.
SHMITE, Stella y Nin, María Cristina. Geografía cultura un recorrido teórico a través del diálogo de autores contemporáneos, Revista Huellas, 2007, n 11, pp. 168194.

STERNBERG, Ernest. The Economy of Icons. Connecticut: Praeger, 1999.

STERNBERG, Ernest. An Integrative Theory of Urban Design, Journal of the Planning Association, 2007, vol. $66, n^{\circ} 3$, pp. $265-278$

TILL, Karen. Artistic and activist memory-work: approaching place-based practice, Memory studies, 2008, vol. 1, n 1 , pp. 99-113.

TUAN, Yi Fu. Topophilia a study of environmental perception, attitudes, and values. New York: Columbia University Press, 1974

TUAN, Yi Fu. Space and Place the perspective of experience. Minneapolis: University of Minnesota Press, 2001.

TUNSTRÖM, Moa. The vital city: constructions and meanings in the contemporary Swedish planning discourse, TPR: Town Planning Review, 2007, vol. 78, $\mathrm{n}^{\circ}$ 6, pp. 681-698.

WHITE, Edward. Path portal place appreciating public space in urban environments. Tallahassee: Architectural media Ltda. 1999.

YI, Xie; BATRA, Rajeev and SIQING, Pen. An Extended Model of Preference Formation between Global and Local Brands: The Roles of Identity Expressiveness, Trust and Affect, Journal of International Marketing, 2015, vol. 23, n 1, pp. 50-71.

ZUKIN, Sharon. The urban landscape. En: Cuthbert, Alexander (ed.). Designing cities critical readings in urban design. Australia: Blackwell publishing, 2003, pp. 177-189.

ZUKIN, Sharon. Reconstructing the authenticity of place, Theory \& Society, 2011, vol. 40, n², pp.161-165. 